\title{
Early Cretaceous lamprophyre dykes in Jiaodong Peninsula, China and implications for subduction-related mantle metasomatism
}

\author{
XIANG WANG ${ }^{1 *}$, ZAICONG WANG ${ }^{1}$, HUAI CHENG ${ }^{1}$, \\ STEPHEN FOLEY ${ }^{2}$, LE XIONG ${ }^{1}$ \\ ${ }^{1}$ School of Earth Sciences, China University of Geosciences, \\ Wuhan 430074, China; *wangx@cug.edu.cn \\ ${ }^{2}$ Department of Earth and Environmental Sciences, \\ Macquarie University, NSW 2109, Australia
}

The sub-continental lithospheric mantle (SCLM) beneath the eastern North China Craton (NCC) was strongly metasomatized by subducted components of different ages before its extensive destruction in Mesozoic ${ }^{[1-2]}$. Although this modification of the SCLM by subducted materials have been well documented ${ }^{[3-6]}$, the degree and extent of mantle metasomatism in the eastern NCC, particularly the region near the Tanlu fault where the significant metasomatism and noticeable cratonic destruction occurred ${ }^{[3,4]}$ are still poorly constrained. Here, we report comprehensive new data on lamprophyre dykes in the Jiaodong Peninsula and combine these with literature data of coeval mantle-derived rocks from the eastern NCC to shed light on this issue.

The lamprophyre dykes sampled from the Jiaodong Peninsula display zircon U-Pb dating ages of around $130 \mathrm{Ma}$, arc-like trace element patterns, radiogenic initial ${ }^{87} \mathrm{Sr} /{ }^{86} \mathrm{Sr}$ (0.70896 to 0.71149$)$ and depleted $\varepsilon N d(t)(-17.2$ to -13.5$)$. These geochemical features are interpreted to reflect an isotopically enriched lithospheric mantle source metasomatized by subducted materials from the continental crust of Yangtze Craton ${ }^{[4-6]}$. The lamprophyre dykes share similar geochemical and isotopic compositions with almost coeval mafic rocks (gabbros, basalts and other lamprophyres) in adjacent regions, which indicates extensive mantle metasomatism by recycled crustal materials over a large area of the lithospheric mantle underneath the eastern NCC. Importantly, the gradual northward increase in $\varepsilon \mathrm{Nd}(\mathrm{t})$ from the southern margin to the interior of the NCC implies a decrease in the influence of subducted continental crustal materials. The volatile-rich nature of these Early Cretaceous mafic rocks and the coeval extensive destruction of the NCC reflects the additional effect of hydration of the mantle by subduction of the Paleo-Pacific plate from the east ${ }^{[7,8]}$.

[1] Wu et al. (2019) Annu. Rev. EPS. 47, 173-195. [2] Zhu et al. (2015) SCES. 58, 1523-1537. [3] Ma et al. (2014) GCA. 124, 250-271. [4] Dai et al. (2016) Lithos. 240-243, 327-336. [5] Yang et al. (2012) Lithos. 155, 422-460. [6] Zhao et al. (2009) SCES. 52, 1295-1318. [7] Xia et al. (2013) EPSL, 361, 85-97. [8] Liang et al. (2019) J. Geol. 127, 343-362. 